\title{
ELECTROCARDIOGRAMS OF MARATHON RUNNERS IN 1962 COMMONWEALTH GAMES
}

\author{
BY \\ W. G. SMITH, K. J. CULLEN, AND I. O. THORBURN \\ From Sir Charles Gairdner and Royal Perth Hospitals, Perth, Western Australia
}

Received September 18, 1963

The Seventh Commonwealth Games was held in Perth, Western Australia, in November 1962. The opportunity was taken to obtain electrocardiograms on the marathon runners before and after the race. Similar observations are rather scanty, and it is apparent that more data are required from larger numbers of all types of athletes of international status. In addition to a short-term study of the present type, information is needed on the prognostic significance of the changes in the cardiogram. Do these, at times, indicate a harmful effect on the myocardium? Conversely does regular strenuous exercise prolong life (White, 1959; Morris et al., 1953)?

Beckner and Winsor (1954) discussed the cardiovascular adaptations to prolonged physical effort. They studied 40 normal non-runners and 155 male marathon runners who had at least five years' training. The main features of the electrocardiograms of the runners at rest were relatively slow heart rates, vertical or semivertical electrical patterns, large voltage of the QRS complexes, and tall T and $U$ waves. Radiologically the hearts were enlarged, but immediately after a race the transverse diameters decreased considerably. Repeat cardiograms immediately after a marathon race showed an increase in amplitude of the P, QRS, and T complexes. In one patient there was a significant depression of the ST segment. Several of these observations had originally been made in a very early cardiogram study of marathon runners by Bramwell and Ellis (1931).

Beswick and Jordan (1961) reported on the electrocardiograms of 60 male athletes at the 1958 Commonwealth Games at Cardiff. They confirmed the earlier findings of Bechner and Winsor and added new vectorcardiographic data. Their findings were discussed as evidence of increased vagal activity and physiological right ventricular hypertrophy.

Karvonen (1959), in a study of champion long-distance skiers who continued the sport until old age, noted bradycardia, slow conduction at atrial and ventricular level, high voltage, and cardiac enlargement, the latter especially before the start of a race. A retrospective study indicated that these skiers survived on the average seven years longer than non-skiing controls.

\section{Subjects AND Methods}

The present study deals with 21 competitors in the marathon race at the 1962 Commonwealth Games at Perth, Western Australia. The cardiograms of all competitors were taken before the race and of 18 soon after its completion. The 21 competitors came from five continents (Africa, Asia (Pakistan), Australasia, Europe, and North America (Canada)). Their athletic performance was of better than average quality. The eventual winner of the race had previously won the 1962 European Games marathon, and his performance time for the 1962 Commonwealth Games event was a new Games record. According to the competitors, the weather conditions were excellent for such an event. The temperature during the day averaged $64^{\circ} \mathrm{F}$. $\left(17 \cdot 8^{\circ} \mathrm{C}\right.$.) and the humidity was 80 per cent. 
A general physical examination before the race showed no abnormalities. The resting cardiograms were taken about 32 hours before the race, between 7.30 and 9.0 a.m. The 18 post-race tracings were obtained as soon as possible after each competitor had finished part or all of the 26-mile course. Fifteen of the tracings were obtained within half an hour of the runner finishing his race. Three tracings were obtained about two hours after the race at the "Games Village" hospital. All cardiograms were taken with the subject in the supine position by means of portable Sanborn and Cardiotrace electrocardiographs, which were correctly standardized. The conventional 12 leads were taken with, in addition, lead III taken on deep inspiration (IIIR) in 12 men. The position of the heart in the chest was determined by the methods of Wilson et al. (1944). The P-R and QRS intervals were taken as the maximum width in any one lead. The rate was measured in lead V4 in order to counteract any nervous tachycardia during the early part of the tracing.

Pulse rates were also obtained from 10 runners within half a minute of completing the race, including five of those in the first six places. Considerable persuasion and tact had to be used to obtain the co-operation of the runners following their ordeal. Some of the runners did not want to lie stationary immediately after the race, and, in any event, were involved in the usual confusion of officials, press reporters, and wellwishers.

\section{RESULTS}

The results are set out in the Table.

Heart and Pulse Rates. Before the race, the heart rates as measured on the electrocardiograph averaged 56 beats a minute (38-78), and after the race 80 beats a minute (52-100). Pulse rates of 10 runners taken within half a minute of the end of the race averaged 127 beats a minute (106145). The average heart rate of the first six to finish was higher than that of the remaining runners, both before and after the race. The average pre-race rate of the first six was 60 a minute (50-70) compared with 55 a minute (30-78) of the remainder. The average immediate post-race pulse rate of five of the first six to finish was 137 a minute (125-145) compared with 118 a minute (106-131) of five of the remainder who finished the race. The average half- to two-hour post-race heart rate of five of the first six runners was 87 a minute (65-100) compared with 78 a minute $(50-100)$ of the remainder.

Electrocardiographic Position of Heart in Chest. The heart was vertical or semivertical in 11 runners. The position was intermediate in 8 , horizontal in 1 , and semi-horizontal in 1 other. No significant positional changes occurred after the race.

$P$ Waves. These were of normal duration and height before the race. After the race the $P$ waves were slightly wider in 8 , taller in 11 , and smaller in 3 . Their duration averaged $0.073 \mathrm{sec}$. before the race $(0.05-0.08 \mathrm{sec}$.) and $0.08 \mathrm{sec}$. $(0.07-0.010 \mathrm{sec}$.) after the race. $P$ wave amplitude before the race averaged $1.47 \mathrm{~mm} .(0.5-2.5 \mathrm{~mm}$.) and after the race $1.92 \mathrm{~mm} .(1.0-3.0 \mathrm{~mm}$.$) .$

$P-R$ Interval. The P-R interval averaged $0.19 \mathrm{sec} .(0.14-0.28 \mathrm{sec}$.) at rest, and after the race it decreased slightly or showed no change, and the average figure was $0 \cdot 17 \mathrm{sec}$. $(0 \cdot 12-0 \cdot 24 \mathrm{sec}$.). In no runner did the $\mathbf{P}-\mathbf{R}$ interval increase after the race.

Duration of $Q R S$ Complex. The widest QRS complex in any lead averaged $0.089 \mathrm{sec}$. at rest $(0.07-0.10 \mathrm{sec}$.) compared with $0.086 \mathrm{sec}$. $(0.07-0.11 \mathrm{sec}$.) after the race.

QRS Abnormalities. Five athletes had RSR' or W complexes in lead V1 (the so-called "incomplete right bundle-branch block"). An additional two runners had slurring of the S wave in V1. These features did not change significantly after the race.

$R$ Waves in Lead II. The amplitudes of $\mathrm{R}$ waves in lead II averaged $14.9 \mathrm{~mm}$. $(5-28 \mathrm{~mm}$.) at rest and $15.0 \mathrm{~mm} .(5 \cdot 0-27 \mathrm{~mm}$.) after the race.

$R$ Wave in $A V F$. The tallest $\mathrm{R}$ wave in AVF was $25 \mathrm{~mm}$. and averaged $11 \cdot 7 \mathrm{~mm} .(4-25 \mathrm{~mm}$.) at rest and $12 \cdot 1 \mathrm{~mm}$. $(2-23 \mathrm{~mm}$.) after the race. Three runners had an $R$ wave greater than $17 \mathrm{~mm}$.

$R$ Waves in Pracordial Leads. The tallest $\mathrm{R}$ waves were usually present in lead V4. The average value at rest was $25.9 \mathrm{~mm}$. (14-35 mm.) and after the race $25 \mathrm{~mm}$. (17-32 mm.).

$S$ Waves in Pracordial Leads. The deepest $\mathrm{S}$ wave was usually in lead V2 and averaged $25 \mathrm{~mm}$. at rest (15-38 mm.) and $25 \mathrm{~mm}$. (13-35 mm.) after the race. 
TABLE

Electrocardiograms of 21 Marathon RunNers Before and After the Race

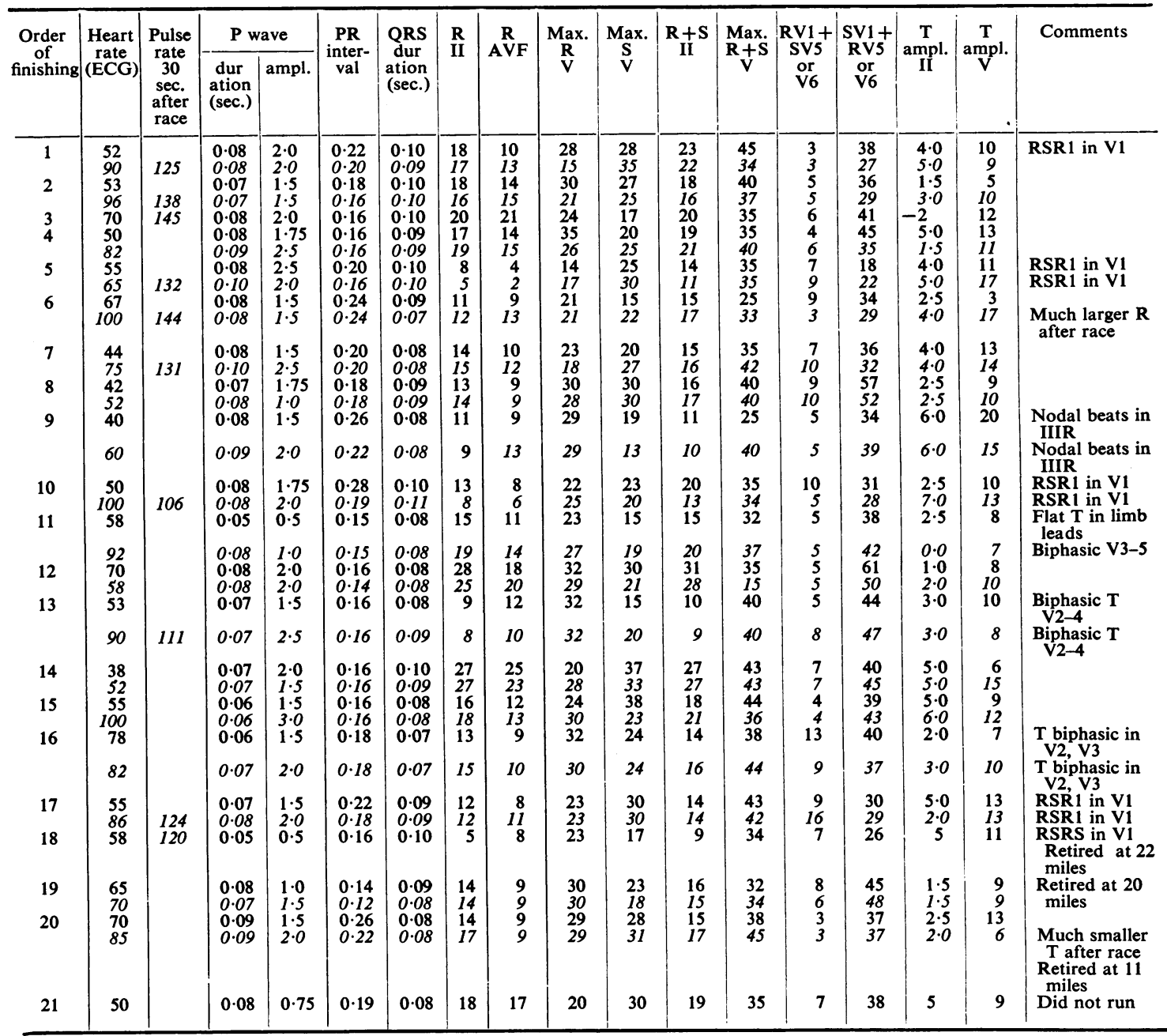

Italics refer to the findings after the race

$R+S$ in Lead II. The mean value was $17 \cdot 1 \mathrm{~mm} .(9-31 \mathrm{~mm}$.$) at rest and 17 \cdot 4 \mathrm{~mm} .(9-28 \mathrm{~mm}$. after the race.

Greatest $R+S$ Voltage in Pracordial Leads. The greatest $\mathrm{R}+\mathrm{S}$ voltage occurred with equal frequency in leads V2, V3, and V4. The mean value was $36 \cdot 3 \mathrm{~mm}$. $(25-45 \mathrm{~mm}$.) at rest and $37 \cdot 2$ $\mathrm{mm}$. (33-45 mm.) after the race.

$S V 1+R V 5$ or $R V 6$. The mean value was $38.5 \mathrm{~mm}$. (18-61 mm.) at rest, and $37 \mathrm{~mm}$. (22$52 \mathrm{~mm}$.) after the race. Sixteen subjects had values over $35 \mathrm{~mm}$., the maximum normal figure quoted by Sokolow and Friedlander (1949).

$R V 1+S V 6$. This gave a mean value of $6.6 \mathrm{~mm}$. (3-13 mm.) before, and $6.6 \mathrm{~mm} .(3-16 \mathrm{~mm}$. after the race.

Amplitude of $T$ Wave in Lead II. This averaged $3.2 \mathrm{~mm}$. (2-6 mm.) before, and $3.5 \mathrm{~mm}$. (0-7 $\mathrm{mm}$.) after the race. 
FIG. 1.-Electrocardiogram showing bradycardia, high voltage of QRS complex, tall $\mathrm{T}$ waves and $\mathrm{U}$ wave in left chest leads (Runner 14).

Amplitude of Tallest $T$ in Pracordial Leads. Before the race the average height was $9.9 \mathrm{~mm}$. (3-20 mm.). After the race the $T$ wave increased to a mean value of $11.4 \mathrm{~mm}$. $(6-17 \mathrm{~mm}$.). The tallest $\mathrm{T}$ waves occurred almost equally in V3, V4, and V5. In 8 runners the $\mathrm{T}$ waves were taller after the race, in 4 they were smaller, and in 6 they were almost unchanged.

$S-T$ Segments. All the tracings showed variable degrees of S-T elevation due to early repolarization. One runner showed depression of the $S-T$ segment of less than $0.5 \mathrm{~mm}$. after the race, 


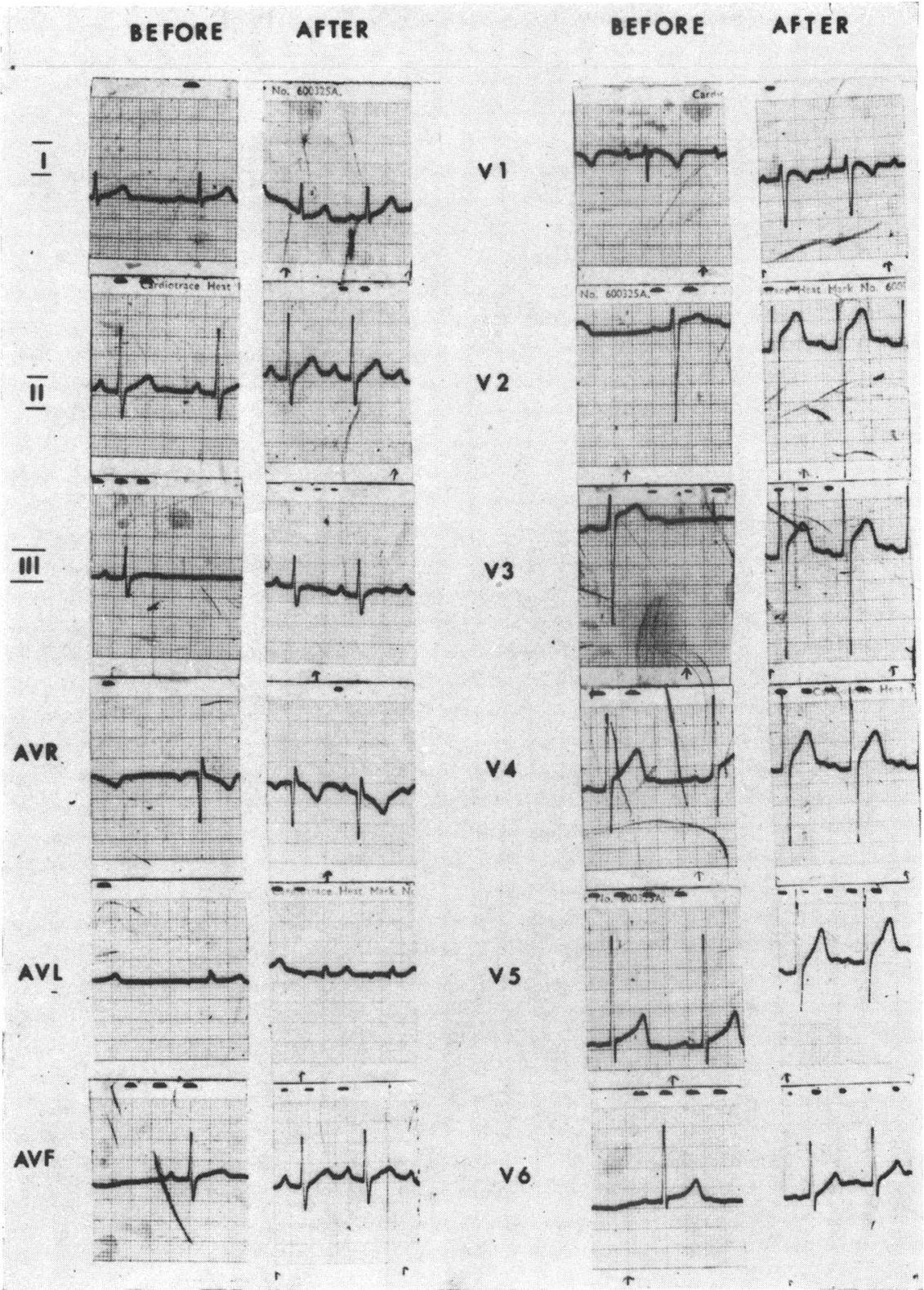

FIG. 2.-Electrocardiogram of the marathon winner showing partial right bundle-branch block (Runner 1).

and the $\mathrm{T}$ waves became flat in the limb leads and biphasic in leads V3, V4, and V5. There were no other significant $\mathrm{S}-\mathrm{T}$ changes after the race.

Intrinsicoid Deflection. These measurements are probably not accurate with direct writing electrocardiographs. Apart from the tracings with the pattern of "incomplete right bundle-branch block," the measurements were normal.

$Q-T$ Interval. All measurements corrected for the heart rate were within normal limits and did not alter significantly after the race.

$U$ Waves. These were well seen in leads V2 to V5 and in some tracings were more conspicuous after running. 


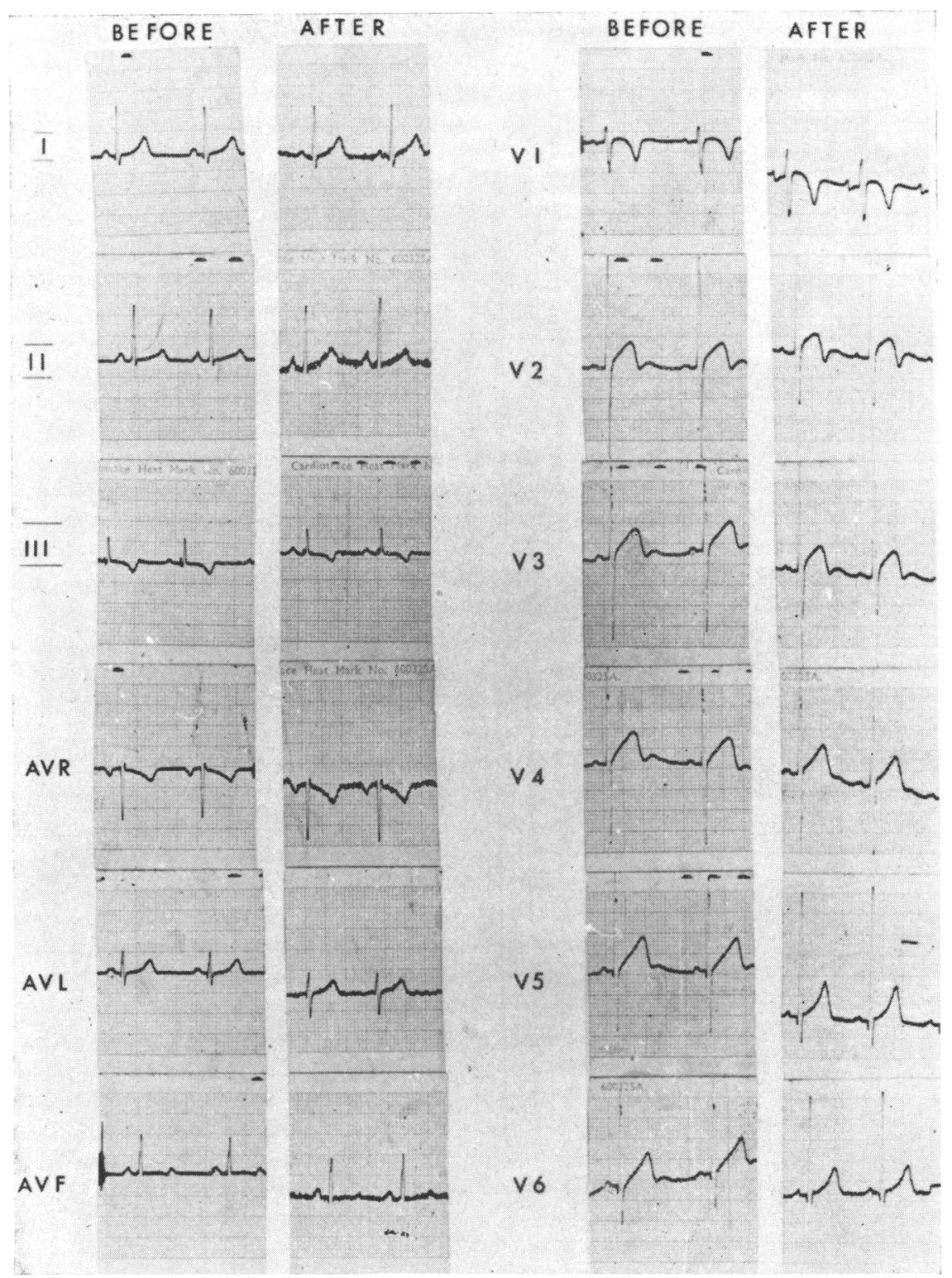

FIG. 3.-Electrocardiogram of a Uganda runner showing the "juvenile pattern" of $T$ waves in V2, V3, and V4 (Runner 13).

\section{Discussion}

These electrocardiographic findings at rest are similar to those of Beckner and Winsor (1954), namely bradycardia, high voltage of QRS complex, large $T$ waves, and rather prominent $U$ waves (Fig. 1). Of the 21 athletes, 16 showed the voltage criteria of left ventricular hypertrophy described by Sokolow and Friedlander (1949). The findings after the race differ a little, in that the $\mathbf{P}$ and $T$ waves did not invariably increase in amplitude and duration as in the series of Bechner and Winsor; in several runners the reverse happened.

The frequency of so-called "partial right bundle-branch block" was confirmed (Fig. 2), but it is 


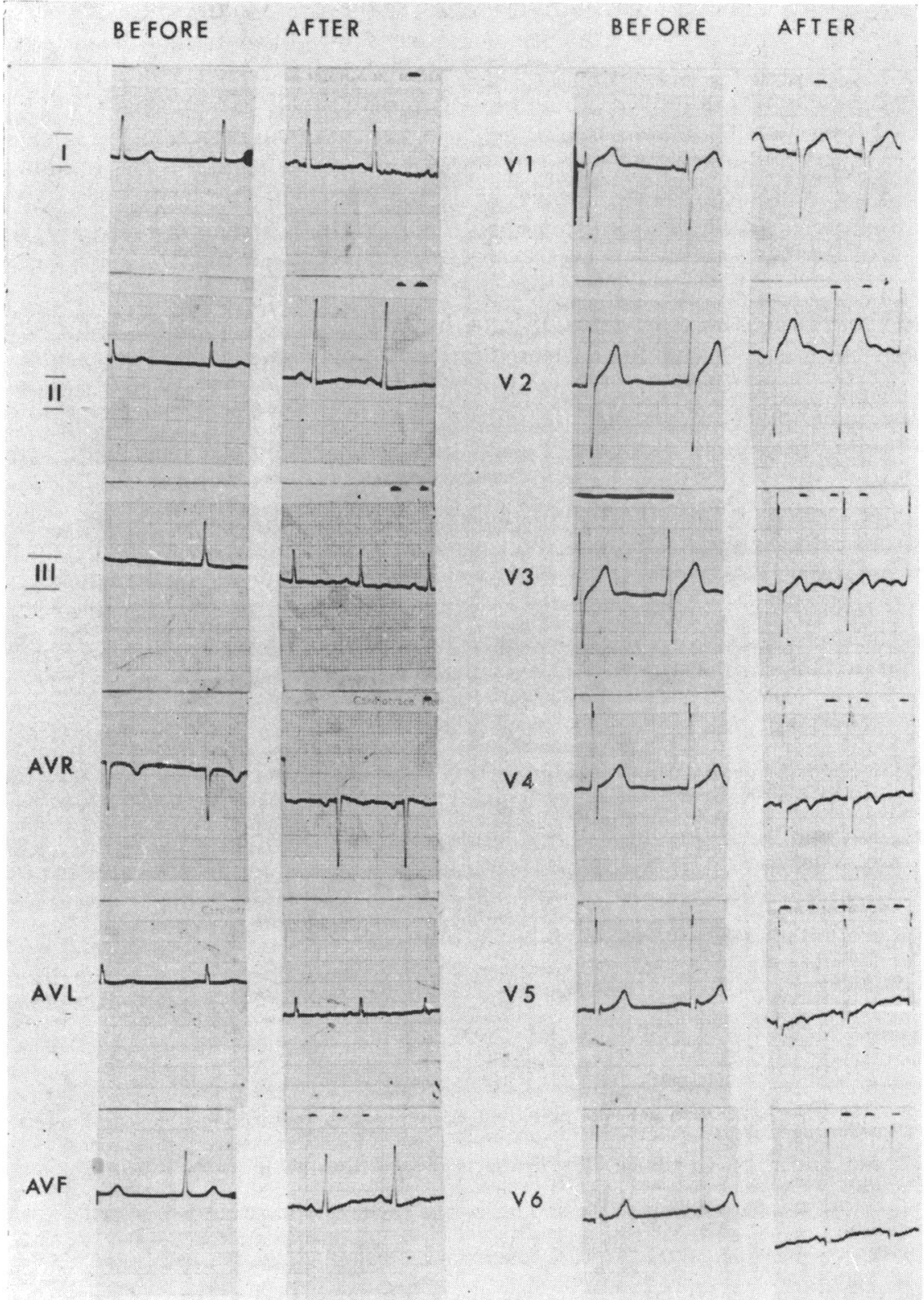

Fig. 4.-Electrocardiogram showing $T$ wave inversion in left ventricular leads after the race (Runner 11).

difficult to agree with Bechner and Winsor, or with Karvonen that this may represent an indication of right ventricular strain. This feature on the cardiogram is relatively common in normal subjects (Hiss and Lamb, 1962); it may readily be produced by placing the V1 electrode in a slightly high or rightward position. Finally, if it is significant, it is more likely to represent slightly delayed conduction due to a dilated right ventricle, as in atrial septal defect. At least part of the cardiac enlargement in endurance athletes is due to increased diastolic volume of the right ventricle (Karvonen, 1959). 
Atrial T waves were not conspicuous in this series, as they were in the series of Bechner and Winsor. There was no positive electrocardiographic evidence of right ventricular hypertrophy, although in two subjects the sum of R in V1 and S in V5 exceeded $10.5 \mathrm{~mm}$., which is the upper limit of normal quoted by Sokolow and Friedlander. One runner from Uganda had unusual biphasic $T$ waves in V2, V3, and V4 (Fig. 3). These were unchanged after the race, and represent the so-called "juvenile pattern" of the negro, described by Grusin (1954), Somers and Rankin (1962), and others. One runner showed inverted and biphasic $T$ waves in the left ventricular leads after the race (Fig. 4). It was difficult to draw any definite conclusion about the state of his myocardium from this observation as the changes were non-specific and may well have resulted from hypoglycæmia or from electrolytic disturbances.

As is well recognized, the pulse rates of long-distance marathon runners tend to be lower than normal control subjects, although the measured rate must, of course, depend on nervous anxiety and other factors as in normal subjects. It was of some interest to note that the best runners in this race tended to have higher pulse rates before and immediately after the race than the slower runner. This may simply be due to a greater degree of nervous tension before the race and a more sustained maximum effort.

One purpose in writing this short report is to draw attention to the need for a long-term prospective study of athletes such as these. We suggest that this should be done on an international basis by the various athletic associations, and that international sports medicine bodies might commence a card index system to keep regular records of all outstanding national and international athletes. In the present state of our knowledge it is impossible to assess the true significance of the electrocardiographic and other findings in endurance athletes.

\section{SUMMARY}

Resting electrocardiograms of 21 top-class marathon runners have been analysed. Eighteen tracings were obtained soon after the marathon race in the 1962 Commonwealth Games in Perth. The previous reports of bradycardia with high voltage of $Q R S$ complexes, $T$, and $U$ waves have been confirmed. In some, but not all, the $\mathrm{P}$ and $\mathrm{T}$ waves increased in amplitude after the race. A plea is made for a long-term prospective study of such athletes on an international basis in order to assess the significance of the electrocardiogram and other changes.

We are very grateful to Dr. D. Letham who originally suggested this study. We should also like to thank many other colleagues who helped in various ways in obtaining the cardiograms and pulse rates. The athletes themselves were most co-operative, and it is a pleasure to record our gratitude to them.

\section{REFERENCES}

Beckner, G. L., and Winsor, T. (1954). Cardiovascular adaptations to prolonged physical effort. Circulation, 9, 835.

Beswick, F. W., and Jordan, R. C. (1961). Cardiological observations at the sixth British Empire and Commonwealth Games. Brit. Heart J., 23, 113.

Bramwell, C., and Ellis, R. (1931). Some observations on the circulatory mechanism in marathon runners. Quart. J. Med., 24, 329.

Grusin, H. (1954). Peculiarities of the African's electrocardiogram and the changes observed in serial studies. Circulation, 9, 860.

Hiss, R. G., and Lamb, L. E. (1962). Electrocardiographic findings in 122,043 individuals. Circulation, $25,947$.

Karvonen, M. J. (1959). Effects of vigorous exercise on the heart. In Work and the Heart: Trans. Ist Wisconsin Conference on Work and the Heart, ed. F. F. Rosenbaum and E. L. Belknap, p. 199. Hoeber, New York.

Morris, J. N., Heady, J. A., Raffle, P. A. B., Roberts, C. G., and Parks, J. W. (1953). Coronary heart-disease and physical activity of work. Lancet, $2,1053$.

Sokolow, M., and Friedlander, R. D. (1949). The normal precordial and limb lead electrocardiogram. Amer. Heart J., 38, 665.

Somers, K., and Rankin, A. M. (1962). The electrocardiogram in healthy East African (Bantu and Nilotic) men. Brit. Heart J., 24, 542.

White, P. D. (1959). The advantages of physical fitness. Illinois med. J., 116, 185.

Wilson, F. N., Johnston, F. D., Rosenbaum, F. F., Erlanger, H., Kossman, C. E., Hecht, H., Contrim, N., de Oliverira, R. M., Scarsi, R., and Barker, P. S. (1944). Præcordial electrocardiogram. Amer. Heart J., $27,19$. 